\title{
Bonferroni distances with OWA operators
}

\author{
Fabio Blanco-Mesa \\ Universidad Antonio Nariño \\ 7 Avenue 21-84, 150001, Tunja, \\ Colombia \\ Email: fabio.blanco@uan.edu.co
}

\author{
José M. Merigo-Lindahl \\ Universidad de Chile \\ Av. Diagonal Paraguay 257, \\ Santiago 8330015, Chile. \\ Email.jmerigo@fen.uchile.cl
}

\begin{abstract}
The aim of the paper is to develop new aggregation operators using Bonferroni means, ordered weighted averaging (OWA) operators and some distance measures. We introduce the Bonferroni-Hamming weighted distance, Bonferroni OWA distance, and Bonferroni distances with OWA operators and weighted averages. The main advantages of using these operators are that they allow considering different aggregations contexts, multiple-comparison between each argument and distance measures in the same formulation.
\end{abstract}

\section{INTRODUCTION}

In the literature there are wide ranges of methods for solving decision-making problems. Among these methods, aggregation models are becoming very popular. The development of these aggregation models have created a mathematical discipline called aggregation theory [1]. These models allow modelling great types of relationships and obtaining representative values of the aggregated information. One of the most used models is the ordered weighted averaging OWA operator [2], from which has been developed a great deal of extension in combination with others mathematical models. OWA operator is an instrument that allows aggregating information obtaining a single representative value of the information [3, 4]. From this model, several authors have developed new aggregation operators providing a parameterized family. Some of these new aggregation operators are distance measure for OWA operators [5-7]. These new extensions allow reflecting the attitudinal character of the decision maker at the time of decision-making.

Likewise, a new aggregation operator is proposed by using Bonferroni means [8], which allows making multiple-comparison between input arguments and capturing its interrelationship. The combination of this operator with OWA operator allows involving a product of each argument with the average of the other arguments [1]. Yager [1] suggested generalization of this operator by replacing the simple averaging by other mean type operators. From this application several authors have developed new aggregations operators related to Bonferroni means (BM) and applied on multi-attribute decision-making. Yager [1] and Beliakov [9] proposed a generalized of BM. Xu and Yager [10] proposed intuitionistic fuzzy Bonferroni means and Xia [11] suggested its generalization.

The aim of this paper is to develop new aggregation operators using Bonferroni means, OWA operators and some distance measure. We introduce the BON-HWD, BON-OWAAC and BON-IWOWAD. We are able to include HWD, AC, IW in the same formulation with Bonferroni means and OWA operator. Thus, we get a new group of distance family, which allows analyzing the importance of each distance. Likewise, this new group of distance family is combined with Pichat algorithm to solve group decision-making problems. These new methods are used as previous step to apply Pichat algorithm in order to get different distance between a set of elements and gather each element according to the maximum similarity sub-relations. We develop an illustrative application focused on establishment of efficient, cooperatives and creative workgroups 
according to comparison of creative capabilities of each member. These algorithms allow aggregating information obtained a single value representative of the information according to the parameters of creative levels of each member.

The structure of this paper is as follows: Firstly, we study preliminary concepts, which are composed by a briefly review of Bonferroni means, OWA operators and distance measures. Secondly, we study Bonferroni means and OWA operator in combination with distance measures in order to develop new methods based on hybrid weighted distance, immediate weighted and adequacy coefficient. Thirdly, we propose grouping problems using Pichat algorithm and new methods proposed in section above. Fourthly, we develop an illustrative application to decisionmaking in the formation of creative groups and present the main results. Finally, we present the main conclusions and implications of the research.

\section{PRELIMINARIES}

In this section, we briefly review Bonferroni means, OWA operator, BON-OWA, distance measures and OWAD in order to develop new tools based on distance measures in combination with Bonferroni means and OWA operators.

The Bonferroni mean [8] is another type of mean that can be used in the aggregation process in order to present the information. It can be defined by using the following expression.

$\mathrm{B}\left(\mathrm{a}_{1}, \mathrm{a}_{2}, \ldots, \mathrm{a}_{\mathrm{n}}\right)=\left(\frac{1}{\mathrm{n}} \frac{1}{1-\mathrm{n}} \sum_{\substack{\mathrm{j}=1 \\ \mathrm{j} \neq \mathrm{k}}}^{\mathrm{n}} \mathrm{a}_{\mathrm{j}}^{\mathrm{q}}\right)^{\frac{1}{\mathrm{r}+\mathrm{q}}}$,

where $r$ and $q$ are parameters such that $r, q \geq 0$ and the arguments $a \geq 0$. By rearranging the terms (Yager 2009), it can be also formulate in the following way:

$\mathrm{B}\left(\mathrm{a}_{1}, \mathrm{a}_{2}, \ldots, \mathrm{a}_{\mathrm{n}}\right)=\left(\sum_{\mathrm{k}=1}^{\mathrm{n}} \mathrm{a}_{\mathrm{k}}^{\mathrm{r}}\left(\frac{1}{1-\mathrm{n}} \sum_{\substack{\mathrm{j}=1 \\ \mathrm{j} \neq \mathrm{k}}}^{\mathrm{n}} \mathrm{a}_{\mathrm{j}}^{\mathrm{q}}\right)\right)^{\frac{1}{\mathrm{r}+\mathrm{q}}}$.

The OWA operator [2] provides a parameterized class of mean type of aggregation operators. It can be defined as follows.

Definition 1. An OWA operator of dimension $n$ is a mapping OWA: $\mathrm{R}^{\mathrm{n}} \rightarrow \mathrm{R}$ that has an associated weighting vector $\mathrm{W}$ of dimension $\mathrm{n}$ with $\mathrm{w}_{\mathrm{j}} \in$ $[0,1]$ and $\sum_{\mathrm{j}=1}^{\mathrm{n}} \mathrm{w}_{\mathrm{j}}=1$, such that:

$\operatorname{OWA}\left(\mathrm{a}_{1}, \mathrm{a}_{2}, \ldots, \mathrm{a}_{\mathrm{n}}\right)=\sum_{\mathrm{j}=1}^{\mathrm{n}} \mathrm{w}_{\mathrm{j}} \mathrm{b}_{\mathrm{j}}$,

where $b_{i}$ is the jth largest of the $a_{i}$.
The Bonferroni OWA [1] is mean type aggregation operator. It can be defined by using the following expression.

BON - OWA $\left(\mathrm{a}_{1}, \ldots, \mathrm{a}_{\mathrm{n}}\right)=\left(\frac{1}{n} \sum_{i} a_{i}^{r} O W A_{W}\left(V^{i}\right)\right)^{\frac{1}{\mathrm{r}+\mathrm{q}}},(4)$

where $O W A_{W}\left(V^{i}\right)=\left(\frac{1}{\mathrm{n}-1} \sum_{\substack{\mathrm{j}=1 \\ \mathrm{j} \neq \mathrm{i}}}^{\mathrm{n}} \mathrm{a}_{j}^{q}\right)$ with $\left(V^{i}\right)$

being the vector of all $\mathrm{a}_{j}$ except $\mathrm{a}_{i}$ and $w$ being an $n-1$ vector $W_{i}$ associated with $\alpha_{i}$ whose components $\mathrm{w}_{i j}$ are the OWA weights. Let $W$ be an OWA weighting vector of dimension $n-1$ with components $w_{i} \in[0,1]$ when $\sum_{i} w_{i}=1$. Then, we can define this aggregation as $O W A_{W}\left(V^{i}\right)=\left(\sum_{j=1}^{n-1} w_{i} a_{\pi_{k}(j)}\right)$, where $a_{\pi_{k}(j)}$ is the largest element in the tuple $V^{i}$ and $w_{i}=\frac{1}{n-1}$ for all $i$. Thus, we have observed that this aggregation is equal at the original case. Furthermore, according to [1] the weight vector $w_{i}$ can be stipulated by different ways. One approach is to directly specify the vector W. Other form is using [12] approach $-\sum_{j=1}^{n-1} w_{j} \ln \left(w_{j}\right)$ such as $\sum_{j=1}^{n-1} w_{j} \frac{\mathrm{n}-\mathrm{j}}{n-1}=\alpha, \quad \sum_{j=1}^{n-1} w_{j}=1, \quad 0 \leq w_{j} \leq 1$. Another approach is via BUM function $f$, in which we get $w_{j}=f\left(\frac{j}{n-1}\right)-f\left(\frac{j-1}{n-1}\right)$. Based on this method is develop other approach, which starts with a parameterized family of BUM functions and define the desired aggregation by specifying the value associated parameter [1]. Another parameter function is $f(x)=x^{r}$ for $\mathrm{r}>$ 0 , where from $r$ we get a particular function. Attitudinal character is such that $\alpha=\frac{1}{r+1}$ and if we specify $\alpha$ we can obtain $r=\frac{1-\alpha}{\alpha}[1]$.

The Hamming distance [13] is a useful technique for calculating the differences between two elements, two sets, etc. In fuzzy set theory, it can be useful, for example, for the calculation of distances between fuzzy sets, interval-valued fuzzy sets, intuitionistic fuzzy sets and intervalvalued intuitionistic fuzzy sets. For two sets A and B, the weighted Hamming distance can be defined as follows.

Definition 2. A weighted Hamming distance of dimension $\mathrm{n}$ is a mapping $\mathrm{d}_{\mathrm{WH}}: \mathrm{R}^{\mathrm{n}} \mathrm{XR}^{\mathrm{n}} \rightarrow \mathrm{R}$ that has an associated weighting vector $\mathrm{W}$ of dimension $\mathrm{n}$ with the sum of the weights being 1 and $\mathrm{w}_{\mathrm{j}} \in[0,1]$ such that:

$\mathrm{d}_{\mathrm{WH}}\left(\left\langle\mathrm{x}_{1}, \mathrm{y}_{1}\right\rangle, \ldots,\left\langle\mathrm{x}_{\mathrm{n}}, \mathrm{y}_{\mathrm{n}}\right\rangle\right)=\sum_{\mathrm{j}=1}^{\mathrm{n}} \mathrm{w}_{\mathrm{j}}\left|\mathrm{x}_{\mathrm{i}}-\mathrm{y}_{\mathrm{i}}\right|, \quad$ (5) where $x_{i}$ and $y_{i}$ are the ith arguments of the sets $X$ and $\mathrm{Y}$.

The OWAD operator $[3,14]$ is an aggregation operator that uses OWA operators and distance 
measures in the same formulation. It can be defined as follows for two sets $\mathrm{X}$ and $\mathrm{Y}$.

Definition 3. An OWAD operator of dimension $n$ is a mapping OWAD: $\mathrm{R}^{\mathrm{n}} \mathrm{XR}^{\mathrm{n}} \rightarrow \mathrm{R}$ that has an associated weighting vector $\mathrm{W}, \sum_{\mathrm{j}=1}^{\mathrm{n}} \mathrm{w}_{\mathrm{j}}=1$ and $\mathrm{w}_{\mathrm{j}} \in[0,1]$ such that:

$\operatorname{OWAD}\left(\left\langle\mathrm{x}_{1}, \mathrm{y}_{1}\right\rangle, \ldots,\left\langle\mathrm{x}_{\mathrm{n}}, \mathrm{y}_{\mathrm{n}}\right\rangle\right)=\sum_{\mathrm{j}=1}^{\mathrm{n}} \mathrm{w}_{\mathrm{j}} \mathrm{D}_{\mathrm{j}}$,

where $D_{j}$ represents the $j t h$ largest of the $\left|x_{i}-y_{i}\right|$.

The MOWAD operator is an aggregation operator that uses OWA operators and distance measures in the same formulation. It can be defined as fallows for two sets A and B.

Definition 4. A MOWAD operator of dimension $\mathrm{n}$ is a mapping OWAD: $\mathrm{R}^{\mathrm{n}} \mathrm{xR}^{\mathrm{n}} \rightarrow \mathrm{R}$ that has an associated weighting vector $\mathrm{W}, \sum_{\mathrm{j}=1}^{\mathrm{n}} \mathrm{W}_{\mathrm{j}}=1$ and $\mathrm{w}_{\mathrm{j}} \in[0,1]$ such that:

$\operatorname{MOWAD}\left(\mathrm{d}_{1}, \mathrm{~d}_{2}, \ldots, \mathrm{d}_{\mathrm{n}}\right)=\left(\sum_{\mathrm{j}=1}^{\mathrm{n}} \mathrm{w}_{\mathrm{j}} \mathrm{D}_{\mathrm{j}}{ }^{\lambda}\right)^{1 / \lambda}$,

where $\mathrm{D}_{\mathrm{j}}$ represents the $\mathrm{jth}$ largest of the $d_{i}$ and $d_{i}$ is the individual distance between $\mathrm{A}$ and $\mathrm{B}$. That is, $d_{i}=\left|x_{i}-y_{i}\right| . \lambda$ is a parameter such that $\lambda \in$ $(-\infty, \infty)$.

The OWAWAD operator is a distance measure that uses the WA and the OWA operator in the normalization process of the Hamming distance by using OWAWA operator. Thus the reordering of the individual distance is developed according to the values of the individual formed by comparing two sets. It can be defined as follows for two sets for two sets $X=\left\{x_{1}, x_{2}, \ldots, x_{n}\right\}$ and $Y=\left\{y_{1}, y_{2}, \ldots, y_{n}\right\}$.

Definition 5. An OWAWAD operator is a mapping OWAWAD: $\mathrm{R}^{\mathrm{n}} \times \mathrm{R}^{\mathrm{n}} \rightarrow \mathrm{R}$ of dimension $\mathrm{n}$, if it has an associated weighting vector $\mathrm{W}$, with $\sum_{\mathrm{j}=1}^{\mathrm{n}} \mathrm{w}_{\mathrm{j}}=1$ and $\mathrm{w}_{\mathrm{j}} \in[0,1]$ and a weighting vector $\mathrm{V}$ that affects the WAD, with $\sum_{\mathrm{j}=1}^{\mathrm{n}} \mathrm{v}_{\mathrm{j}}=1$ and $v_{i} \in[0,1]$, such as:

$\operatorname{OWAWAD}\left(\left\langle\mathrm{x}_{1}, \mathrm{y}_{1}\right\rangle,\left\langle\mathrm{x}_{2}, \mathrm{y}_{2}\right\rangle, \ldots,\left\langle\mathrm{x}_{\mathrm{n}}, \mathrm{y}_{\mathrm{n}}\right\rangle\right)=$ $\beta \sum_{\mathrm{j}=1}^{\mathrm{n}} \mathrm{w}_{\mathrm{j}} \mathrm{b}_{\mathrm{j}}+(1-\beta) \sum_{\mathrm{i}=1}^{\mathrm{n}} \mathrm{v}_{\mathrm{i}}\left|\mathrm{x}_{\mathrm{i}}-\mathrm{y}_{\mathrm{i}}\right|$,

where $b_{j}$ is the jth largest of the arguments $\left|x_{i}-y_{i}\right|$ and $\beta \in[0,1]$.

\section{BONFERRONI OWA DISTANCE}

In this section, we briefly review of aggregation operators such as: Bonferroni distance (BD), Bonferroni OWAD (BON-OWAD) and Bonferroni OWAWAD (BON-OWAWAD). Likewise, we present news aggregation operators using Bonferroni means, OWA operator and others distance measure Hibryd Weight distance, Immediate weighted and Adequacy coefficient.

Bonferroni means and distance measures have been studied is new aggregation operators using Bonferroni means, distance measure and OWA operator. This proposal has suggested a new group of operators, such as: Bonferroni distance, Bonferroni OWAD and Bonferroni OWAWAD. For dealing with distance measures using Bonferroni means, the arguments $a_{i}$ and $a_{j}$ are two sets of variables instead of one but methodology is the same. The mains concepts of new group of operators are defined as follows.

Definition 6. Bonferroni distance for two sets $X=$ $\left\{x_{1}, x_{2}, \ldots, x_{n}\right\}$ and $Y=\left\{y_{1}, y_{2}, \ldots, y_{n}\right\}$ is given by: $\operatorname{BD}\left(\left\langle\mathrm{x}_{1}, \mathrm{y}_{1}\right\rangle, \ldots,\left\langle\mathrm{x}_{\mathrm{n}}, \mathrm{y}_{\mathrm{n}}\right\rangle\right)=$

$\left(\frac{1}{n} \sum_{\mathrm{k}=1}^{\mathrm{n}} \mathrm{d}_{\mathrm{i}}^{\mathrm{r}}\left(\frac{1}{\mathrm{n}-1} \sum_{\substack{\mathrm{j}=1 \\ \mathrm{j} \neq \mathrm{k}}}^{\mathrm{n}} \mathrm{d}_{\mathrm{j}}^{\mathrm{q}}\right)\right)^{\frac{1}{\mathrm{r}+\mathrm{q}}}$,

where $d_{i}$ and $d_{j}$ are the individual such that $d_{i}=$ $\left|x_{i}-y_{i}\right|$ and $d_{j}=\left|x_{j}-y_{j}\right|$.

Definition 7. A BON-OWAD distance for two sets $X=\left\{x_{1}, x_{2}, \ldots, x_{n}\right\}$ and $Y=\left\{y_{1}, y_{2}, \ldots, y_{n}\right\}$ is given by:

$\operatorname{BON}-\operatorname{OWAD}\left(\left\langle\mathrm{x}_{1}, \mathrm{y}_{1}\right\rangle, \ldots,\left\langle\mathrm{x}_{\mathrm{n}}, \mathrm{y}_{\mathrm{n}}\right\rangle\right)=$

$\left(\frac{1}{n} \sum_{i} D_{i}^{r} O W A D_{\omega_{i}}\left(V^{i}\right)\right)^{\frac{1}{\mathrm{r}+\mathrm{q}}}$

where $O W A D_{\omega_{i}}\left(V^{i}\right)=\left(\frac{1}{\mathrm{n}-1} \sum_{\substack{\mathrm{j}=1 \\ \mathrm{j} \neq \mathrm{i}}}^{\mathrm{n}} \mathrm{D}_{j}^{q}\right)$ with $\left(V^{i}\right)$ being the vector of all $\left|x_{j}-y_{j}\right|$ except $\left|x_{i}-y_{i}\right|$ and $\omega_{i}$ being an $n-1$ vector $W_{i}$ associated with $\alpha_{i}$ whose components $\mathrm{w}_{i j}$ are the OWA weights. Likewise, $D_{i}$ is the kth smallest of the individual distance $\left|x_{i}-y_{i}\right|$.

Definition 8. A BON-OWAWAD distance for two sets $X=\left\{x_{1}, x_{2}, \ldots, x_{n}\right\}$ and $Y=$ $\left\{y_{1}, y_{2}, \ldots, y_{n}\right\}$ is given by:

$\operatorname{BON}-\operatorname{OWAWAD}\left(\left\langle\mathrm{x}_{1}, \mathrm{y}_{1}\right\rangle, \ldots,\left\langle\mathrm{x}_{\mathrm{n}}, \mathrm{y}_{\mathrm{n}}\right\rangle\right)=\beta \times$

$\left(\frac{1}{n} \sum_{i} D_{i}^{r} O W A D_{\omega_{i}}\left(V^{i}\right)\right)^{\frac{1}{\mathrm{r}+\mathrm{q}}}+\quad(1-\beta) \times$

$\left(\frac{1}{n} \sum_{\mathrm{i}=1}^{\mathrm{n}} \mathrm{D}_{i}^{r} W A D_{V_{i}}\left(V^{i}\right)\right)^{\frac{1}{\mathrm{r}+\mathrm{q}}}$

where $D_{i}$ is the kth smallest of the individual distance $\left|x_{i}-y_{i}\right|$ and $\beta \in[0,1]$. Observe that $\beta=$ 1 forms the BON-OWAD operator and $\beta=0$ the weighted Bonferroni distance (BON-WAD) that is expressed as: 
$\operatorname{BON}-\operatorname{WAD}\left(\left\langle\mathrm{x}_{1}, \mathrm{y}_{1}\right\rangle, \ldots,\left\langle\mathrm{x}_{\mathrm{n}}, \mathrm{y}_{\mathrm{n}}\right\rangle\right)=$

$\left(\frac{1}{n} \sum_{\mathrm{i}=1}^{\mathrm{n}} \mathrm{D}_{i}^{r} W A D_{v_{i}}\left(V^{i}\right)\right)^{\frac{1}{\mathrm{r}+\mathrm{q}}}$

where $W A D_{v_{i}}\left(V^{i}\right)=\left(\frac{1}{\mathrm{n}-1} \sum_{\substack{\mathrm{j}=1 \\ \mathrm{j} \neq \mathrm{k}}}^{\mathrm{n}} \mathrm{D}_{j}^{q}\right)$ with $\left(V^{i}\right)$

being the vector of all $\left|x_{j}-y_{j}\right|$ except $\left|x_{i}-y_{i}\right|$ and $v_{i}$ being an $n-1$ vector $V_{i}$ associated with $\lambda_{i}$ whose components $\mathrm{v}_{i j}$ are the WAD weights. Likewise, $D_{i}$ is the kth smallest of the individual distance $\left|x_{i}-y_{i}\right|$.

In order to understand the BON-OWAD and BON-OWAWAD numerically, let us present a simple example.

Example 1. Let $\mathrm{X}=(0.2,0.5,0.4)$ and $\mathrm{Y}=$ $(0.5,0.1,0.7)$ be two sets of arguments. $w_{i}$ is the weighting vector of the argument $\left|x_{i}-y_{i}\right|$ associated with $\alpha_{i}$ whose components $\mathrm{v}_{i j}$. Here we shall let $\alpha_{1}=0.4, \alpha_{2}=0.7$ and $\alpha_{3}=0.5$. We take $\quad r=\mathrm{q}=1$. In addition: $V^{1}=\mid 0.5-$ $0.1 \mid$ and $|0.4-0.7|, \quad V^{2}=\mid 0.2-$ $0.5 \mid$ and $|0.4-0.7| \quad$ and $\quad V^{3}=\mid 0.2-$ $0.5 \mid$ and $|0.5-0.1|$. Using this get:

$O W A D_{v_{1}}\left(V^{1}\right)=0.4 \times(|0.5-0.1|+$

$|0.4-0.7|)=0.28 ; \quad O W A D_{v_{2}}\left(V^{2}\right)=0.7 \times$

$(|0.2-0.5|+|0.4-0.7|)=0,42$;

$O W A D_{v_{3}}\left(V^{3}\right)=0.5 \times(|0.2-0.5|+$

$|0.5-0.1|)=0.35$.

$B O N-O W A D=\left(\frac{1}{3} \times((|0.2-0.5| \times 0.28)+\right.$

$(|0.5-0.1| \times 0.42)+(|0.4-0.7| \times$

$0.35)))^{0.5}=0.345$.

Since, BON-OWAD is part of BON-OWAWAD corresponding to $\beta \times\left(\frac{1}{n} \sum_{i} D_{i}^{r} O W A D_{\omega_{i}}\left(V^{i}\right)\right)^{\frac{1}{\mathrm{r}+\mathrm{q}}}$, now we develop the other part $(1-\beta) \times$ $\left(\frac{1}{n} \sum_{\mathrm{i}=1}^{\mathrm{n}} \mathrm{D}_{i}^{r} W A D_{V_{i}}\left(V^{i}\right)\right)^{\frac{1}{\mathrm{r}+\mathrm{q}}} . \quad v_{i}=(0.1,0.2,0.1) \quad$ is the weighting vector associated with WAD and $\beta=0.3$. Using this get:

$$
\begin{aligned}
& W A D_{v_{1}}\left(V^{1}\right)=0.1 \times(|0.5-0.1|+ \\
& |0.4-0.7|)=0.07 ; \quad W A D_{v_{2}}\left(V^{2}\right)=0.2 \times \\
& (|0.2-0.5|+|0.4-0.7|)=0.12 ; \\
& W A D_{v_{3}}\left(V^{3}\right)=0.1 \times(|0.2-0.5|+ \\
& |0.5-0.1|)=0.07 \\
& B O N-W A D=\left(\frac{1}{3} \times((|0.2-0.5| \times 0.07)+\right. \\
& (|0.5-0.1| \times 0.12)+(|0.4-0.7| \times \\
& 0.07)))^{0.5}=0.3 .
\end{aligned}
$$

$B O N-O W A W A D=0.3 \times 0.345+(1-0.3) \times$
$0.300=0.3135$

Let us discuss the properties of BON-OWAD. Note that the proofs are trivial and thus omitted.

Theorem 1: (Commutativity-OWA aggregation). Assume $f$ is the BON-OWAD operator, then $f\left(\left\langle x_{1}, y_{1}\right\rangle, \ldots,\left\langle x_{n}, y_{n}\right\rangle\right)=f\left(\left\langle c_{1}, d_{1}\right\rangle, \ldots,\left\langle c_{n}, d_{n}\right\rangle\right)$. Theorem 2: (Commutativity-OWA distance measure). Assume $f$ is the BON-OWAD operator, then

$f\left(\left\langle x_{1}, y_{1}\right\rangle, \ldots,\left\langle x_{n}, y_{n}\right\rangle\right)=f\left(\left\langle x_{1}, y_{1}\right\rangle, \ldots,\left\langle x_{n}, y_{n}\right\rangle\right)$.

Theorem 3: (Monotonicity). Assume $f$ is the BON-OWAD operator; if $\left|x_{i}-y_{i}\right| \geq\left|c_{i}-d_{i}\right|$ for all $i_{i}$, then

$f\left(\left\langle x_{1}, y_{1}\right\rangle, \ldots,\left\langle x_{n}, y_{n}\right\rangle\right) \geq f\left(\left\langle c_{1}, d_{1}\right\rangle, \ldots,\left\langle c_{n}, d_{n}\right\rangle\right)$.

Theorem 4: (Bounded). Assume $f$ is the BONOWAD operator, then

$\min \left\{\left|x_{i}-y_{i}\right|\right\} \leq f\left(\left\langle x_{1}, y_{1}\right\rangle, \ldots,\left\langle x_{n}, y_{n}\right\rangle\right) \leq$

$\max \left\{\left|x_{i}-y_{i}\right|\right\}$.

Theorem 5: (Idempotency). Assume $f$ is the BON-OWAD operator; if $\left|x_{i}-y_{i}\right|=a$ for all $i$, then

$f\left(\left\langle x_{1}, y_{1}\right\rangle, \ldots,\left\langle x_{n}, y_{n}\right\rangle\right)=\mathrm{a}$.

Theorem 6: (Non-negativity). Assume $f$ is the BON-OWAD operator then

$f\left(\left\langle x_{1}, y_{1}\right\rangle, \ldots,\left\langle x_{n}, y_{n}\right\rangle\right) \geq 0$.

Theorem 7: (Reflexivity). Assume $f$ is the BONOWAD operator then

$f\left(\left\langle x_{1}, y_{1}\right\rangle, \ldots,\left\langle x_{n}, y_{n}\right\rangle\right)=0$.

The hybrid-weighted distance [15] is a distance measure that unifies weighted distance (WD) and ordered weighted distance (OWD) (Xu and Chen, 2008) in the same formulation. It can be defined as follows.

Definition 9. A hybrid weighted distance measure is a mapping HWD: $\mathrm{R}^{\mathrm{n}} \mathrm{xR}^{\mathrm{n}} \rightarrow \mathrm{R}$ of dimension $\mathrm{n}$, it has an associated weighting vector $\mathrm{V}$ associated with HWD measure, with $\sum_{\mathrm{j}=1}^{\mathrm{n}} \mathrm{v}_{\mathrm{j}}=1, \mathrm{v}_{\mathrm{j}} \geq 0 \mathrm{v}_{\mathrm{j}} \in$ $[0,1]$ and a weighting vector $W$ of the argument $\left|x_{i}-y_{i}\right|$, with $\sum_{\mathrm{j}=1}^{\mathrm{n}} \mathrm{w}_{\mathrm{j}}=0, \mathrm{w}_{\mathrm{j}} \geq 0 \quad \mathrm{w}_{\mathrm{j}} \in[0,1]$ and $m$ is a balancing coefficient which plays a role of balance, such as:

$\operatorname{HWD}(\mathrm{x}, \mathrm{y})=\left(\sum_{\mathrm{k}=1}^{\mathrm{n}} \mathrm{v}_{\mathrm{j}} \Delta\left(\mathrm{x}_{\sigma(\mathrm{j})}, \mathrm{y}_{\sigma(\mathrm{j})}\right)\right)^{1 / \lambda}, \lambda>0,(13)$ where $\Delta\left(x_{\sigma(j)}, y_{\sigma(j)}\right)$ is the $j h t$ largest of weighted arguments $\Delta\left(x_{j}, y_{j}\right)$. Here $\Delta\left(x_{j}, y_{j}\right)=$ $m w_{i}\left|x_{i}-y_{i}\right|^{\lambda}, i=1,2, \ldots n$.

Definition 10. A Bonferroni Hybrid Weighted distance for two sets $X=\left\{x_{1}, x_{2}, \ldots, x_{n}\right\}$ and $Y=$ $\left\{y_{1}, y_{2}, \ldots, y_{n}\right\}$ is given by: 
$\operatorname{BON}-\operatorname{HWD}\left(\left\langle\mathrm{x}_{1}, \mathrm{y}_{1}\right\rangle, \ldots,\left\langle\mathrm{x}_{\mathrm{n}}, \mathrm{y}_{\mathrm{n}}\right\rangle\right)=$

$\left(\left(\frac{1}{n} \sum_{i} D_{i}^{r} H W D_{v_{i}}\left(V^{i}\right)\right)^{1 / \lambda}\right)^{\frac{1}{\mathrm{r}+\mathrm{q}}}$,

where $H W D_{w_{i}}\left(V^{i}\right)=\left(\frac{1}{1-\mathrm{n}} \sum_{\substack{\mathrm{j}=1 \\ \mathrm{j} \neq \mathrm{i}}}^{\mathrm{n}} v_{i} n\left(D_{j}^{q}\right)^{\lambda}\right)$ with

$\left(V^{i}\right)$ being the vector of all $\left|x_{j}-y_{j}\right|$ except $\left|x_{i}-y_{i}\right|, w_{i}$ being an $n-1$ vector $V_{i}$ associated with $\alpha_{i}$ whose components of the argument $\left|x_{i}-y_{i}\right|$ are weights, a weighting vector $v_{i}$ associated with the HWD and $n$ is a balancing coefficient which plays a role of balance. Likewise, $D_{i}$ is the kth smallest of the individual distance $\left|x_{i}-y_{i}\right|$.

Furthermore, as we can see, if $\mathrm{v}_{\mathrm{j}}=1 / \mathrm{n}$ for all $\mathrm{j}$, we get the Bonferroni Minkowski distance (BMD), that is expressed as:

BON $-\mathrm{WD}\left(\left\langle\mathrm{x}_{1}, \mathrm{y}_{1}\right\rangle, \ldots,\left\langle\mathrm{x}_{\mathrm{n}}, \mathrm{y}_{\mathrm{n}}\right\rangle\right)=$

$\left(\left(\frac{1}{n} \sum_{\mathrm{i}=1}^{\mathrm{n}} \mathrm{D}_{\mathrm{i}}^{\mathrm{r}}\left(\frac{1}{1-\mathrm{n}} \sum_{\substack{\mathrm{j}=1 \\ \mathrm{j} \neq \mathrm{i}}}\left(D_{j}^{q}\right)^{\lambda}\right)\right)^{1 / \lambda}\right)^{\frac{1}{\mathrm{r}+\mathrm{q}}}$,

if $\lambda=1$ we obtain Bonferroni weighted distance (BWHD), if $\lambda=0$ we can obtain Bonferroni geometric distance (BGD) and if $\lambda=2$ we can obtain Bonferroni weighted Euclidean distance (BWED).

Likewise, if $w_{i}=1 / n($ where $n=1 / 1-n)$ for all $\mathrm{i}$, we get the Bonferroni hybrid distance (BON-HD), that is expressed as:

$\mathrm{BON}-\mathrm{HD}(\mathrm{x}, \mathrm{y})=$

$\left(\left(\frac{1}{n} \sum_{\mathrm{i}=1}^{\mathrm{n}} \mathrm{D}_{\mathrm{i}}^{\mathrm{r}}\left(\sum_{\substack{\mathrm{j}=1 \\ \mathrm{j} \neq \mathrm{i}}}^{\mathrm{n}} v_{i}\left(D_{j}^{q}\right)^{\lambda}\right)\right)^{1 / \lambda}\right)^{\frac{1}{\mathrm{r}+\mathrm{q}}}$,

Definition 11. An IWOWAD operator of dimension $\mathrm{n}$ is a mapping IWOWAD: $\mathrm{R}^{\mathrm{n}} \mathrm{xR}^{\mathrm{n}} \rightarrow \mathrm{R}$ that has an associated weighted vector $\mathrm{W}$ of dimension $\mathrm{n}_{\mathrm{j}} \in[0,1]$ and $\sum_{\mathrm{j}=1}^{\mathrm{n}} \mathrm{w}_{\mathrm{j}}=1$, such that:

$\operatorname{IWOWAD}\left(\left\langle\mathrm{x}_{1}, \mathrm{y}_{1}\right\rangle, \ldots,\left\langle\mathrm{x}_{\mathrm{n}}, \mathrm{y}_{\mathrm{n}}\right\rangle\right)=\sum_{\mathrm{j}=1}^{\mathrm{n}} \hat{\mathrm{v}}_{\mathrm{j}} \mathrm{b}_{\mathrm{j}}$,

where $b_{j}$ is the jth largest of the $\left|x_{i}-y_{i}\right|$, each $\left|x_{i}-y_{i}\right|$ has associated a WA $v_{i}, v_{j}$ is the associated WA of $b_{j}$, and $\hat{v}_{j}=\left(w_{j} v_{j} / \sum_{\mathrm{j}=1}^{\mathrm{n}} \mathrm{w}_{\mathrm{j}} v_{j}\right)$.

In this case, if $w_{j}=1 / n$ for all $\mathrm{j}$, we get the weighted Hamming distance and if $v_{j}=1 / n$ for all $\mathrm{j}$, the OWAD operator. This measure was also extended using OWAAC and OWAIMAM for getting IWOWAAC and IWOWAIMAM ([16].
Definition 12. Bonferroni immediate weights for two sets $X=\left\{x_{1}, x_{2}, \ldots, x_{n}\right\}$ and $Y=$ $\left\{y_{1}, y_{2}, \ldots, y_{n}\right\}$ is given by:

$\operatorname{BIW}\left(\left\langle\mathrm{x}_{1}, \mathrm{y}_{1}\right\rangle, \ldots,\left\langle\mathrm{x}_{\mathrm{n}}, \mathrm{y}_{\mathrm{n}}\right\rangle\right)=$

$\left(\frac{1}{n} \sum_{\mathrm{i}=1}^{\mathrm{n}} \mathrm{a}_{\mathrm{k}}^{\mathrm{r}} I W_{\omega_{i}}\left(V^{i}\right)\right)^{\frac{1}{\mathrm{r}+\mathrm{q}}}$,

where $I W_{\omega_{i}}\left(V^{i}\right)=\left(\frac{1}{1-\mathrm{n}} \sum_{\substack{\mathrm{j}=1 \\ \mathrm{j} \neq \mathrm{k}}}^{\mathrm{n}}\left(v_{j} / \sum_{\mathrm{j}=1}^{\mathrm{n}} v_{j}\right) \mathrm{a}_{j}^{q}\right)$

with $\left(V^{i}\right)$ being the vector of all $a_{j}$ except $a_{i}, \omega_{i}$ being an $n-1$ vector $W_{i}$ associated with $\alpha_{i}$ whose components $\mathrm{w}_{i j}$ are the weighting vector and a weighting vector $v_{i}$ associated with the WA.

Definition 13. A BON-IWOWAD distance for two sets $X=\left\{x_{1}, x_{2}, \ldots, x_{n}\right\}$ and $Y=$ $\left\{y_{1}, y_{2}, \ldots, y_{n}\right\}$ is given by:

BON - IWOWAD $\left(\left\langle\mathrm{x}_{1}, \mathrm{y}_{1}\right\rangle, \ldots,\left\langle\mathrm{x}_{\mathrm{n}}, \mathrm{y}_{\mathrm{n}}\right\rangle\right)=$

$\left(\frac{1}{n} \sum_{\mathrm{k}=1}^{\mathrm{n}} \mathrm{D}_{\mathrm{k}}^{\mathrm{r}} I W O W A D_{\omega_{i}}\left(V^{i}\right)\right)^{\frac{1}{\mathrm{r}+\mathrm{q}}}$,

where

$$
\operatorname{IWOWAD} \omega_{\omega_{i}}\left(V^{i}\right)=\left(\frac{1}{1-\mathrm{n}} \sum_{\substack{\mathrm{j} \neq 1 \\ \mathrm{j} \neq \mathrm{k}}}^{\mathrm{n}}\left(v_{j}\right)\right.
$$

$\left.\left.\sum_{\mathrm{j}=1}^{\mathrm{n}} v_{j}\right) \mathrm{D}_{j}^{q}\right)$ with $\left(V^{i}\right)$ being the vector of all $\left|x_{j}-y_{j}\right|$ except $\left|x_{i}-y_{i}\right|$ and $\omega_{i}$ being an $n-1$ vector $W_{i}$ associated with $\alpha_{i}$ whose components $\mathrm{w}_{i j}$ are the OWA weights and a weighting vector $v_{i}$ associated with the WA. Likewise, $D_{i}$ is the kth smallest of the individual distance $\left|x_{i}-y_{i}\right|$. In this case, if $w_{j}=1 / n$ for all $\mathrm{j}$, we get the BONIWD and if $v_{j}=1 / n$ for all $\mathrm{j}$, the BON-OWAD operator. If one of the sets is empty, we get the Bonferroni immediate weight (BIW) operator.

\section{CONCLUSIONS}

We have studied OWA operators, some distance measures, hybrid-weighted distance and Bonferroni means in order to propose new aggregation operators. We have introduced new aggregation operators using HWD, AC and IW in the same formulation with Bonferroni means and OWA operator. The methods introduced are called BON-OWAAC, BON-HWD and BONIWOWAD. The main advantages on using these operators are that they allow considering continuous aggregations, multiple-comparison between each argument and distance measures in the same formulation. Besides, each method has specific advantage. For BON-OWAAC the differences between two sets is establishes a threshold in the comparison process when one set 
is higher than the other so the results are equal from this point. For BON-HWD the distance and ordered weighted reflect the importance of the argument and its ordered position, i.e. it considers the importance of ordered position of each value rather than the importance of each value itself. For BON-IWOWAD ordered weighted average considers the degree of importance of the information. Likewise, we have obtained other methods such as BAC, BIW, BON-WD and BONHD. Thus, we get a new group of distance family, which allows analysing the importance and interrelationship of each distance.

Furthermore, these new algorithms can be used in different fields. Firstly, they used in fields such as: sports teams, strategy marketing and entrepreneurship. Secondly, they allow aggregating objective and subjective information from different sources. Thirdly, they allow considering continuous aggregations, multiplecomparison between each argument.

\section{REFERENCES}

1. Yager, R.R. (2009). On generalized Bonferroni mean operators for multi-criteria aggregation. International Journal of Approximate Reasoning, 50(8), 1279-1286.

2. Yager, R.R. (1988). On ordered weighted averaging aggregation operators in multicriteria decision-making. IEEE Transactions on Systems, Man and Cybernetics B, 18(1), 183-190.

3. Merigó, J.M. (2009). Nuevas Extensiones a los Operadores OWA y su Aplicación en los Métodos de Decisión. Doctoral Thesis, Universitat de Barcelona.

4. Blanco-Mesa, F.R. (2015). Técnicas para la toma de decisiones en contextos inciertos: identificación de oportunidades socioeconómicas en el ámbito deportivo. Doctoral Thesis, Universitat de Barcelona.

5. Merigó, J.M. \& Gil-Lafuente, A.M. (2008). the generalized adequacy coefficient and its application in strategic decision making. Fuzzy Economic Review, XIII:17 - 36.

6. Merigó, J.M. \& Gil-Lafuente, A.M. (2008). Using the OWA operator in the Minkowski distance. International Journal of Computer Science, 3,147-157.

7. Merigó, J.M. \& Gil-Lafuente, A.M. (2013). A method for decision making based on generalized aggregation operators.
International Journal of Intelligent Systems, 28(5),453-473.

8. Bonferroni, C. (1950). Sulle medie multiple di potenze. Bollettino dell'Unione Matematica Italiana, 5(3-4), 267-270.

9. Beliakov, G., James. S., Mordelová, J., Rückschlossová, T. \& Yager, R.R. (2010). Generalized Bonferroni mean operators in multi-criteria aggregation. Fuzzy Sets and Systems, 161(17), 2227-2242.

10. Xu, Z. \& Yager, R.R. (2011). Intuitionistic fuzzy Bonferroni means. IEEE Transantion on Systems Man and Cybernetics, Part B, Cybernetics, 41(2), 568-78.

11. Xia, M., Xu, Z. \& Zhu, B. (2012). Generalized intuitionistic fuzzy Bonferroni means. International Journal of Intelligent Systems, 27(1), 23-47.

12. O’Hagan, M. (1990). Using maximum entropy-ordered weighted averaging to construct a fuzzy neuron. In: Proceedings of the 24th Annual IEEE Asilomar Conference on Signals, Systems and Computers. Pacific Grove, 618-623.

13. Hamming, R.W. (1950). Error detecting and error correcting codes. Bell System Technical Journal, 29(2), 147-160.

14. Merigó, J.M. \& Gil-Lafuente, A.M. (2010). New decision-making techniques and their application in the selection of financial products. Information Sciences, 180(11), 2085-2094.

15. Xu, Z. (2008). Hybrid weighted distance measures and their application to pattern recognition. In: Fyfe C, KIm D, Lee S-Y, Yin $\mathrm{H}$ (eds) Intelligent Data Engineering and Automated Learning-IDEAL. Springer Berlin Heidelberg, Daejeon, 17-23.

16. Merigó. J.M. \& Gil-Lafuente, A.M. (2012). Decision making techniques with similarity measures and owa operators. SORT Statistics and Operations Research Transactions, 36(1), 81-102. 